\title{
BRINCADEIRAS E BRINQUEDOS NA ATUALIDADE: BREVE CONTRIBUIÇÃO ARTICULANDO A INFÂNCIA E A ESCOLA ${ }^{1}$
}

Daniela de Castro Silva ${ }^{2}$ Marcele Teixeira Homrich ${ }^{3}$

\section{Resumo}

Este breve estudo analisa as brincadeiras e brinquedos na atualidade articulando a infância e a escola. Para a realização do mesmo, utilizou-se de pesquisa bibliográfica, desenvolvida através de três pontos: primeiramente, apresenta-se se forma sucinta elementos referente à história da infância, do brinquedo e da escola. Na sequência, trata-se das características dos brinquedos e infância da atualidade, e ao final, articula-se a relação da instituição escolar com a nova infância e os brinquedos. O estudo mostrou que as mudanças sociais que ocorreram na história influenciaram na formação da infância contemporânea e na relação desta com os brinquedos e brincadeiras, cabendo à escola a tarefa de articular passado e presente, assim como produzir reflexões acerca das produções da atualidade.

Palavras - chave: Infância; brinquedo; brincadeira; escola; atualidade.

\footnotetext{
${ }^{1}$ Texto derivado da monografia apresentada por Daniela de Castro Silva, orientanda pela professora Marcele T. Homrich, como requisito para conclusão junto ao curso de Pedagogia do Instituto Cenecista de Ensino Superior de Santo Ângelo - IESA.

${ }^{2}$ Daniela de Castro Silva - Graduada em Pedagogia pelo Instituto Cenecista de Ensino Superior de Santo Ângelo (IESA-CNEC);

${ }^{3}$ Marcele Teixeira Homrich - Rua Marquês Tamandaré, 712, apt 401 - Santo Ângelo/RS. E-mail: celehomrich@ibest.com.br Telefone: (55) 33142024 Psicóloga, Especialista em Educação Infantil e Mestre em Educação (UNISINOS). Atualmente é Doutoranda em Educação pela Universidade Federal do Rio Grande do Sul (UFRGS) e Docente do Instituto Cenecista de Ensino Superior de Santo Ângelo - IESA.
} 
O que caracteriza os brinquedos da atualidade, quais os significados das brincadeiras na infância e as suas implicações na escola? Eis a questão norteadora da presente investigação que se utilizou de pesquisa bibliográfica, por esta apresentar, através de pressupostos teóricos, as informações para a compreensão e aprofundamento da temática. Foram utilizados como referência autores como: Ariès (1981), Postman (1999), Heywood (2004), Dornelles (2005), Corazza (2000-2002-2005), Levin (2007), entre outros. No decorrer do estudo pesquisou-se a história da infância, do brinquedo e da escola, caracterizou-se a infância contemporânea e suas brincadeiras e, por fim, ressaltaram-se as implicações da relação da escola com os brinquedos e a infância da atualidade.

\section{A infância, os brinquedos e a escola: breves considerações históricas}

Em cada período de desenvolvimento da sociedade construíram-se concepções diferentes em relação à infância. O estudo desta história possibilita refletir sobre o modo de relação atual desse universo com a criança.

Ariès $^{4}$ (1981) afirma que a infância não existia na Antiguidade, o que existia era o ser pequeno, visto como um adulto em miniatura, o qual participava de todas as atividades do mundo adulto. A diferenciação "adulto-infância" não existia, sendo que as crianças eram consideradas adultos imperfeitos.

A criança era indistinta dos adultos, nos trajes, brinquedos, jogos, trabalho, linguagem, sexualidade, diferindo das outras pessoas apenas por serem menores. Não tinham um estatuto específico, ou seja, participavam livremente na rua dos eventos do cotidiano e de todas as atividades da comunidade: ritos, costumes, festas, lutas, jogos, e assim, elas cresciam. Também não havia uma preocupação de excluí-las das conversas dos adultos, havendo certa

\footnotetext{
${ }^{4}$ Importante salientar que Ariès faz uma leitura da realidade Européia. Consideramos importante o autor pelo fato do Brasil ser colonizado pelos Europeus, concluindo que tal continente exerce força na constituição cultural no Brasil. Toma-se como base para tal argumentação o trabalho de Norbert Elias $(1993,1994)$
} 
promiscuidade, sendo comum dormirem na mesma cama com os pais ou com criados que cuidavam delas, sob esse aspecto Ariès salienta que:

A consciência da particularidade infantil, essa particularidade que distingue essencialmente a criança do adulto, não existia. Por essa razão, assim que a criança tinha condições de sobreviver sem o cuidado e as atenções de suas mães ou amas, entre as idades de 5 e 7 anos, as crianças eram lançadas na grande comunidade dos homens. Elas se juntavam aos adultos em seus afazeres, deveriam trabalhar para se sustentar, esperava-se que crescessem rápido. (1981, p. 156).

Dornelles (2005) assegura que crianças e adultos trabalhavam, viviam e testemunhavam nascimentos, doenças e mortes, da mesma maneira que participavam da vida pública, das festas, guerras, audiências, execuções, etc. Denota-se disso, a inexistência de uma infância com características próprias, sobre esse aspecto Postman afirma que "no período medieval a criança é, numa palavra, invisível. De todas as características que diferenciam a Idade Média da Moderna, nenhuma é tão contundente quanto à falta de interesse pelas crianças" (1999, p. 33).

Durante décadas as crianças não eram reconhecidas nas suas especificidades, esse descaso se fazia perceber na altíssima taxa de mortalidade infantil, que tornou urgente a construção de políticas médico-higienistas, no entanto, tais preocupações limitavam-se às questões de saúde e, vencida a etapa considerada perigosa, a criança era, sem demora, inserida no mundo dos adultos. A criança entra em cena tendo como principal função a luta pela sobrevivência (ARIÈS, 1981).

Nessa perspectiva, a fase da infância seria caracterizada pela ausência da fala e de comportamentos esperados, considerados como manifestações "irracionais". A infância se contrapõe à vida adulta, pois os comportamentos considerados "racionais", ou providos da razão, seriam encontrados apenas no indivíduo adulto, identificando, assim, o adulto como o homem que pensa, raciocina e age, com capacidade para alterar o mundo que o cerca, tal capacidade, portanto, não seria possível às crianças. 
As relações entre pais e filhos eram meramente formais, os pais eram seres inacessíveis às crianças consideradas inferiores, e, por isto, suas demandas e necessidades não eram valorizadas ao ponto de serem atendidas. Nesse período, a passagem da criança pela família era muito breve e insignificante, este ser estava sempre à margem da família. A mortalidade infantil era muito grande e comum, os pais não se abalavam, pois as crianças que morriam não contavam, os pais tinham muitos filhos e logo viria outro para substituir a criança que morresse:

Contudo um sentimento superficial da criança - a que chamei "paparicação"- era reservado à criancinha em seus primeiros anos de vida, enquanto ela ainda era uma coisinha engraçadinha. As pessoas se divertiam com a criança pequena como um animalzinho, um macaquinho impudico. Se ela morresse então, como muitas vezes acontecia, alguns podiam ficar desolados, mas a regra geral era não fazer muito caso, pois uma outra criança logo substituiria (ARIÈS, 1981,p.10).

Os brinquedos e as brincadeiras da época medieval eram comuns às crianças e aos adultos. Ariès (1981) afirma que as crianças brincavam normalmente com brincadeiras da idade adulta, ou seja, ao mesmo tempo em que brincavam com bonecas, os meninos de quatro a cinco anos praticavam o arco, jogavam cartas, xadrez e participavam de jogos de adultos. Os adultos brincavam de acender vela com os olhos vendados, como se tivessem 15 anos, além disso, as crianças manuseavam armas sem nenhuma restrição por parte dos adultos.

Segundo Kishimoto (1999), brinquedo é o objeto que representa certas realidades, é um substituto dos objetos reais, para que possa ser manipulado pelas crianças, sendo todo objeto utilizado para brincar ou jogar. Brincadeira é a ação voluntária e consciente que a criança desempenha ao concretizar as regras do jogo, ao mergulhar na ação lúdica. (KISHIMOTO, 1999). Percebe-se assim, que na época medieval não existia uma separação entre as brincadeiras e brinquedos reservados às crianças e as brincadeiras e jogos dos adultos, os mesmos eram comuns a ambos.

Com o transcorrer dos anos, algumas especificidades se evidenciam, como a idade de sete anos, que era a idade fixada para a criança começar a trabalhar ou entrar na escola. 
Assim, antes dos sete anos os brinquedos e brincadeiras que predominavam eram bonecas, esconde-esconde, cavalo de pau, cantar, dançar e, após os sete anos, surge como brincadeira a caça, cavalos, armas e teatro e, dessa forma, a criança abandona o traje da infância (ARIÈS, 1981).

Com o avanço da Revolução Industrial e das novas tecnologias, na segunda metade do século XX, os brinquedos tradicionais foram substituídos por brinquedos de plástico, os quais reproduziam cada vez mais o mundo dos adultos. Aparecem aviões, trens, bonecas na moda, com roupas e acessórios, carros de combate, munições... Brinquedos rápidos e cheios de novas tecnologias: sons, ritmos, ruídos, com destrezas e piruetas.

Com o passar do tempo, e principalmente com a invenção da imprensa, percebeu-se um maior destaque em relação à criança, pois diante dessa invenção ocorreu a divisão entre os que sabiam ler e os que não sabiam. Assim, as crianças foram sendo excluídas do mundo adulto, mas incluídas em um novo mundo destinado só para elas. Sob esse aspecto, Postman afirma que "como as crianças foram expulsas do mundo adulto, tornou-se necessário encontrar um outro mundo que elas pudessem habitar. Este outro mundo veio a ser conhecido como infância." (1999, p.34).

Em vista disso, passam a considerar as falas das crianças, seus desejos, suas brincadeiras, tudo o que envolve a criança passa a ser digno de atenção. Segundo Heywood (2004) se reconheceria que as crianças precisavam de tratamento especial, antes que pudessem integrar o mundo dos adultos.

No que se refere à história da escola, no período medieval, as crianças eram educadas sem que existissem instituições especiais, não aprendiam a alfabetização básica no sistema escolar fundamental, adquiriam conhecimentos na prática, junto com os adultos, durante um período que prestavam serviços a outra família. Elas eram enviadas de suas casas como 
serviçais ou aprendizes, ou seja, o serviço doméstico se confundia com a aprendizagem, como uma forma muito comum de educação.

Sob esse aspecto Ariès menciona que:

\begin{abstract}
Era por meio do serviço doméstico que o mestre transmitia a uma criança, filho de outro homem, a bagagem de conhecimentos, a experiência prática e o valor humano que pudesse possuir. A transmissão do conhecimento de uma geração a outra era garantida pela participação familiar das crianças na vida dos adultos, em toda parte onde se trabalhava, e também onde se jogava ou brincava, as crianças se misturavam aos adultos, dessa maneira elas aprendiam a viver, através do contato de cada dia. (1981, p. 228).
\end{abstract}

Ressalta-se que esse tipo de educação durou até por volta do século XV, pois nesse período as escolas surgiram isolando as crianças do mundo dos adultos, então, a educação passou a ser fornecida cada vez mais pela instituição escolar.

Desde o final do século XV surge o desaparecimento do "adulto-pequeno" sendo substituído por um novo indivíduo: sujeito da prática institucional, o aprendiz, o aluno. Surge a escola como um instrumento da iniciação social, da passagem do estado da infância ao do adulto. Essa mudança ocorreu, pois se desejava isolar a juventude do mundo "sujo" dos adultos para mantê-la na inocência.

A prática institucional se dá a partir da desqualificação da aprendizagem da criança
realizada na rua ou em meio aos adultos e no contato com eles. Prática de um
dispositivo de enclausuramento dos infantis nos colégios, a que se dá o nome de
'escolarização'. Na medida em que as crianças passam a constituir, na
Modernidade, uma população específica - a infantil -, esta precisa ser governada de
uma forma particular, ou seja, quando são identificadas como infantis, separadas
dos outros grupos etários, impõe-se a obrigação de administrá-las e, para isso, a
necessidade do conhecimento das suas especificidades. (DORNELLES, 2005,
p.57).

De acordo com Dornelles (2005) a escola surge como um espaço específico para a educação, que controla o tempo, organiza os horários e atua na formação das crianças. A partir do século XIX, a escola se alia à família para produzir, cada vez mais, a educação de seus filhos.

Nesse sentido, Corazza (2000) discute que o conceito de infância se modifica influenciado por alguns fatores como: emergência de um sistema de educação, mudanças na 
estrutura familiar, desenvolvimento do capitalismo, surgimento de um espírito de benevolência e aumento da maturidade emocional dos pais. Esse conceito torna-se mais elaborado durante os séculos XVIII e XIX, quando, então, a criança passa a ser considerada um componente essencial da família e da sociedade, e seus direitos passam a ser protegidos pelo estado.A infância começa sua caminhada histórica no sentido de ser supostamente o momento mais privilegiado da vida, e, com esforço da medicina, da psicologia e do direito, a infância ganha o foco de pesquisa no final do século XIX.

Conforme Kuhlmann (2001) as instituições de educação da criança estão relacionadas com as questões da história da infância, por isso é a partir do surgimento do sentimento sobre a infância que a instituição escolar se ampliou e ganhou lugar social. Com o surgimento desse novo conceito, aparecem também as primeiras instituições educacionais, permitindo a concepção de que os adultos "compreenderam a particularidade da infância e a importância tanto moral como social e metódica das crianças em instituições especiais, adaptadas a essas finalidades [...]" (ARIÈS, 1981, p.193).

Passado o período de descoberta da infância, o homem foi cada vez mais se aprimorando e estudando sobre essa fase da vida humana que hoje tem obtido um papel de destaque na sociedade contemporânea. Diante disso, percebe-se a infância como uma construção social, e em tempos atuais, não se restringe apenas à preocupação familiar, mas também a uma preocupação social. Surgem assim, leis, estatutos, deveres e direitos para com as crianças em nossa sociedade, reiterando-se, dessa forma, que cada vez mais elas têm adquirido papel central nas relações familiares e sociais.

Desse modo, a infância passa de uma época em que não era reconhecida para outra em que passa ser valorizada. Atualmente, a infância é distinta daquela de tempos atrás. Hoje a criança não só é reconhecida, como possui o seu espaço, fala sobre seus desejos, insatisfações e opiniões. As crianças consomem tanto ou até mais que os adultos, elas influenciam, tomam 
decisões, diferentemente das crianças de outros tempos que apresentavam uma posição de passividade a tudo o que os pais lhes davam ou falavam:

Do ponto de vista da economia, estas crianças constituem, dentre o público segmentado, o 'segmento infantil' específico de consumo, integrado por pequenos, mas representativos consumidores. São independentes, tomam decisões, influem nas seleções dos adultos e consomem muito. Pesquisas apontam que as crianças dessa geração 'pode tudo' selecionam seus programas de TV sozinhas; decidem sobre a marca e os equipamentos do computador; vão a viagens, acampamentos, festas, sem a companhia dos familiares; escolhem suas roupas, cinema, CDs, lanches. Deste modo, possuem poder de decisão em produtos que extrapolam o mundo dos brinquedos e guloseimas, e influenciam as decisões de compra de toda família. (CORAZZA, 2002, p.18).

Nesse contexto a criança é imersa em uma lógica contemporânea, produzindo discursos específicos sobre essa fase, assim como a produção de produtos destinados a elas. Entre os produtos ofertados à criança, encontramos os mais diversos, entre eles os tecnológicos, os quais surgem a partir da demanda do trabalho adulto, facilitando o jogo do mercado capitalista, que adentram no mundo da infância como objetos de consumo. São eles: computadores, celulares, vídeo-games, mp3 $(4,5,6 \ldots)$, câmeras digitais, entre outros.

Dornelles (2005) salienta que a infância da atualidade não é só a infância das novas tecnologias, há também aquela infância que é diferente da idealizada, aquela que está à margem de tudo, ou seja, das novas tecnologias, dos games, da Internet. Crianças e adolescentes que estão, muitas vezes, fora de suas casas, sem acesso aos produtos de consumo, que sobrevivem nos bueiros da vida urbana. Dornelles denomina essas crianças como sendo crianças ninjas, argumentando que:

\footnotetext{
Atualmente, as crianças ninjas são encontradas dentro de esgotos, embaixo de viadutos e pontes, capazes de viver em bueiros à semelhança dos guerreiros dos desenhos e filmes das Tartarugas Ninjas. São vistas diariamente nas esquinas com sinaleiras fazendo malabarismos, vendendo coisas, pedindo esmolas, isso marca um tipo de infância inventada como marginal, perigosa, aquela que, mesmo sem o adulto para protegê-la e ampará-la, produz um cotidiano que possibilite sua sobrevivência. Infância que apavora porque consegue viver sem o adulto. (2005, p. 78).
}

Assim como existem crianças ninjas, há também a cyber-infância, que trata da infância globalizada contemporânea, isto é, aquela infância afetada pelas novas tecnologias. Essa nova 
abordagem da infância é vista como perigosa pelos adultos, tanto que estes possuem um sentimento de medo diante da mesma, pois ela escapa ao seu "controle", e certamente, esse medo surge porque os adultos supõem não possuir um saber suficiente para controlá-la ou porque não se consegue melhor governá-la.

Pensar acerca da cyber-infância é pensar problematizando os efeitos dos fenômenos intelectuais e culturais que afetam as infâncias atuais. Pensar sobre estas infâncias é pensar diferente do que pensava antes. Pensar a infância naquilo que ela nos incita, nos perturba, nos marca, nos atormenta, nos cativa. (DORNELLES, 2005, p.79).

Referente ao surgimento da cyber-infância, pode-se compreender que após a Revolução Industrial os brinquedos ficaram cada vez mais aperfeiçoados, sendo que a criança imagina, inventa, mas é o brinquedo que comanda seus passos na brincadeira, basta apenas seguir os seus comandos.

Depois de tão alto grau de aperfeiçoamento, o objeto-brinquedo acaba por brincar sozinho; com efeito, ele se torna protagonista de uma brincadeira solitária que é auto-suficiente, não sendo necessário que a criança brinque. Para que ela iria brincar, se o brinquedo brinca sozinho? A criança é privada do prazer de brincar inventando, de criar encenando ao acaso, ficando então fixa, imóvel, estática, enquanto o objeto é que se movimenta, age, fala, canta brinca e faz por ela. (LEVIN, 2007 , p. 25).

Surgem os videogames com uma variedade de modelos e jogos. Sendo que, o que atrai as crianças nesses jogos é o poder. Elas brincam de terem os poderes da imagem, elas têm a sensação de serem livres, de fazerem o que bem quiserem com o aparelho, quando na verdade a sequência e o curso do jogo estão matematicamente predeterminados do princípio ao fim. Essas novidades causam efeitos como a alienação da criança que se apega à tela, a qual cria e re-cria uma realidade "virtual" pela qual a criança acaba sendo afetada. (LEVIN, 2007)

O computador ganha a preferência das crianças, argumenta Machado:

Os brinquedos e jogos, inanimados, podem até atrair a curiosidade da criança caso ela tenha sido estimulada pela família a utilizar e se divertir com tais recursos em sua experiência anterior, mas invariavelmente os jogos, cores, sons, recursos multimídia, o teclado, o mouse, a possibilidade de apertar botões e acionar programas, abrir janelas e variar as brincadeiras irão fazer com que o computador ganhe a disputa. (2007, p.10). 
Essas transformações acabam sendo influenciadas pelas brincadeiras em frente ao computador, televisão, celular, mp3-4-5. Segundo Dornelles (2005) muitas crianças de hoje não estão acostumadas a agir ou pedir licença para saber ou pensar, elas fazem tudo isso, muitas vezes, sem a permissão do adulto. Assim, a infância contemporânea passa a ser os seres que nos escapam, pois destes pequenos, pouco ou quase nada se sabe, destes se têm medo por não saber fazer aquilo que com tranquilidade dão conta, ou seja, não se sabe o que muitos deles sabem.

Com o capitalismo, os produtos se tornam cada vez mais descartáveis e o que vale não é a relação (com o brinquedo), mas o quanto é necessário ter "sempre mais" e, diante desses brinquedos, a infância do século XXI brinca cada vez menos, pois os brinquedos se constituem em objetos de valor, de posse e hierarquia. São brinquedos para possuir e não para brincar, são brinquedos que não promovem a ação da criança, pois ela fica parada horas e horas em frente às máquinas, então, o que acaba ocorrendo é que o brinquedo brinca por ela. (Levin, 2007)

\section{Articulações possíveis: do velho ao novo}

A criança e a infância passaram por mudanças sociais e históricas, e, consequentemente, a escola sofreu modificações. Percebeu-se que o surgimento da escola esteve atrelado ao surgimento da infância. Nesse sentido, a escola, com a preocupação de ensinar as crianças antes que elas entrassem no universo adulto, exercia sua função de normatizar, proteger as crianças das coisas supostamente erradas do mundo adulto. Sendo que, a partir da Revolução Industrial, houve alterações nas exigências escolares e o ensino voltou-se para a formação técnica, visando o trabalho e a aprendizagem de uma profissão.

No que se refere à tarefa da escola, na atualidade, estaria compreender as diferenças e perceber que os seus alunos e seus brinquedos mudaram, portanto, se faz necessário que a 
escola mantenha uma relação compreensão X reflexão, não uma aceitação acomodada, e sim uma possibilidade de produzir relações entre passado e presente. A escola deve compreender o novo, mas sem perder as referências, ou seja, possibilitar às crianças de hoje o que era brincar na época de seus pais. Possibilitar um vínculo entre passado e presente, valorizando o antigo e o novo, permitindo assim, que as crianças recebam o passado como herança geracional $^{5}$ e possam apropriar-se dessa história, pois sem o antigo o novo não existiria. (LEVIN, 2007)

Para Corazza:

\begin{abstract}
Ou aprendemos as lições deste tempo e fazemos os diferentes e suas culturas entrarem, efetivamente, em nossos currículos e práticas pedagógicas, ou vamos acabar cedendo nosso lugar de educadores críticos para os a - críticos funk, futebol, ruas, gangues, drogas, Internet, prostituição infantil, filmes da Disney, tele turma, tele-namoro, teles sexo. Ou a diferença se torna, de uma vez por todas, a principal argila de nosso trabalho pedagógico e curricular, ou seremos educadores perdidos, à deriva, fora de nosso tempo. E o que é mais grave: não estaremos educando nossos alunos para um porvir plural e criativo, em que a educação faça diferença. (2005, p. 21).
\end{abstract}

Assim, a instituição escolar precisa ser um lugar onde o aluno seja o agente do processo: que faz, pergunta, pesquisa, descobre, cria, aprende, enquanto a construção do conhecimento, acontece dentro de uma prática pedagógica, na qual a busca do aperfeiçoamento se faz em conjunto entre educador e o educando. Sobre esse processo Corazza afirma que:

\begin{abstract}
Nos dias de hoje os movimentos sociais e a teorização cultural não podem mais ser os mesmos, o currículo e a Pedagogia não podem agir e nem pensar como antes, os professores e alunos não podem educar nem serem educados como até então. Eles saem da camisa-de-força da categoria social para explodir os seus entendimentos e práticas em mil pequenos marcadores sociais. (2005, p.18).
\end{abstract}

Destaca-se que a educação não ocorre somente na escola, ela também acontece em diferentes locais pedagógicos tais como: bibliotecas, TVs, filmes, jornais, revistas, brinquedos, anúncios, videogames, livros. Portanto, se faz necessário que professores e

\footnotetext{
${ }^{5}$ Conceito apresentado por Levin (2007) proposto a partir da compreensão de um rompimento geracional originado das diferenças extremas entre a infância da atualidade e a do passado. Diferenças entre as infâncias de pais e filhos que impossibilitam um reconhecimento e uma transmissão.
} 
escola entendam que esses locais influenciam na educação das crianças. Esses elementos invadem o espaço escolar, colocando um "molde", estipulando padrões de felicidade, divulgando a idéia de que é preciso "ter" para poder "ser".

Sendo assim, um dos meios que mais influencia na educação das crianças é a televisão, que a priori foi criada para ser utilizada como fonte de lazer e de informação, no entanto, atualmente, ocorre o contrário, pois chegam a nossas casas mensagens de incentivo ao consumo de brinquedos, de filmes, de videogames, de moda, de livros, etc. Dessa forma, com medo de frustrar seus filhos, os pais acabam cedendo aos apelos televisivos, comprando tudo ou quase tudo que é vinculado por esse aparelho.

Então, o que deverá ser feito? Proibir as crianças de assistirem televisão? Sobre essa problemática, Gonçalves pontua que "a questão em si não é proibição de programas televisivos, brinquedos, livros ou outros objetos explorados pela mídia, o que urge é a necessidade de esclarecimento, de uma (re) leitura desses produtos, impossibilitando a infância de ser massacrada.” (2005, p. 16). Portanto, a questão do consumo e suas consequências devem ser discutidas tanto no ambiente escolar quanto no familiar, é importante dialogar, ouvir e alertar, "fazendo pensar" o que está sendo produzido pela mídia, pelos meios de comunicação, assim como pela produção tecnológica.

Nesse sentido, percebemos que a escola da atualidade deverá entrar em um constante processo de (re)pensar, buscando novas formas de conhecimento tanto na prática quanto na teoria, dando maior ênfase às articulações entre o passado e o presente. É de fundamental importância que a escola venha democratizar o acesso ao conhecimento, dispondo de tecnologias de comunicação e informação, das mais diversas formas, desse modo, valorizando a interdisciplinaridade. Essa nova escola deverá preparar o sujeito-aluno para viver em uma sociedade dinâmica e em constante transformação, fazendo do saber uma ferramenta para 
produzir transformações, formando um cidadão crítico, condições estas, fundamentais para a vida na atualidade.

Uma das características da infância contemporânea é a sua nova forma de brincar e os seus brinquedos, sendo que, através destes, ocorre a fragmentação do diálogo gerencial. Segundo Levin (2007) os pais não se reconhecem nessa criança e nem nos seus brinquedos, é difícil para eles aceitar essa diferença entre as gerações, muitos se perguntam por que o filho prefere ficar parado em frente à TV ao invés de correr, subir em árvores. Porém, poucos percebem que essa é uma produção atual, estes são os brinquedos que resultaram de um processo histórico e cultural, os quais devem ser compreendidos por pais e educadores. Estes brinquedos são uma produção de uma época histórica e fazem parte da infância da atualidade.

A tese de Postman (1999) aborda o desaparecimento da infância seguindo o pressuposto de que não existem mais diferenças entre a fase adulta e a infância. São fases da vida que são diferentes, por seus fazeres, seus tempos e sua rotina. De fato, a infância de hoje não é mais a infância do passado. Mas cabe salientar que as formas de brincar, as motivações, os tempos, os espaços são outros, demonstrando a existência da infância, porém de forma diferente. Os modos de entretenimento, os tipos de brincadeiras, a forma de usar o espaço ou o corpo parecem constituir elementos que fazem a diferença, provocando um não reconhecimento de determinado modo de brincar. Há que se saber ler as outras formas de infância que a atual geração inventa.

Tomando como base Levin (2007), os brinquedos desta nova infância são caracterizados por não produzirem ação, criação, ato. $\mathrm{O}$ brinquedo está pronto, basta seguir os seus comandos, a criança acaba sendo uma criança sem corpo, pois o corpo está em outro lugar, ou na tela ou no game. Esses brinquedos são retratos de uma época, em que o capitalismo e as produções em massa dominam, ou seja, o que importa não é a subjetividade de cada um, mas sim o consumo, o "ter", sendo que o "ser" fica esquecido. 
Sendo assim, salienta-se que essa é uma nova geração e, como dito anteriormente, é uma geração que assusta os próprios pais, pois as crianças estão cada vez mais espertas e consumistas, sabem o que está na moda e escolhem o que querem, e isso ocorre desde a mais tenra idade. Nesse sentido, acaba ocorrendo uma fragmentação nas gerações, ou seja, uma ruptura familiar que acaba sendo preenchida pela imagem e pela tela que transmite essa imagem, sobre esses aspectos Levin afirma que:

A quantidade de horas que pais e filhos dedicam às telas, aos trabalhos e especialistas em infância chama a atenção pela desproporção com o outro tempo, de intimidade e de cumplicidade, de contato e desfrute filial, que é próprio do vínculo parental, familiar e social.

A família deixou de ser o veículo privilegiado da transmissão geracional, papel que é desempenhado pelos meios de comunicação social, as imagens transmitidas servem como meio de informação e socialização, tornando-se assim familiares. (LEVIN, 2007, p.124).

Portanto, podemos concluir que a cultura contemporânea não destrói a infância, mas a influencia, criando outro universo referente à infância, tendo "a comunicação digital como meio, a imagem como causa e a velocidade elétrica como efeito." (LEVIN, 2007, p.143). Diante da tela a criança fica sem piscar, perde a criatividade, o poder de imaginar, e consequentemente perde a linguagem, ou seja, a criança fala cada vez menos, pois se falar se desconcentra e perde o jogo. A linguagem visual compete agressivamente com a expressão linguística e está vencendo a disputa, em detrimento da riqueza verbal, corporal, gestual e escrita. (LEVIN, 2007)

Cabe à escola apropriar-se dos brinquedos atuais. Por exemplo, se a criança fala muito em um monstro do jogo de vídeo game, por que não fazer um projeto sobre o monstro, construir maquetes, confeccionar o próprio monstro? Envolver as crianças com novas possibilidades, mostrar que elas podem usar o universo maquinal para criar, imaginar e construir.

Para concluir, a infância da atualidade é marcada pela tecnologia, sendo caracterizada por um rompimento geracional, onde pais e filhos não conseguem se reconhecer uns nos 
outros pelas diferenças que se colocam entre as gerações. Os brinquedos do século XXI são caracterizados por uma produção de passividade marcada pelo capitalismo, pois não produzem ação e criação. A escola tem a tarefa de "ler" os elementos que essa infância apresenta, e assim possibilitar uma vinculação entre passado e presente, de modo que as crianças possam reconhecer essas formas de brincar do passado a partir das experiências produzidas no presente.

Este breve estudo bibliográfico centrou-se na concepção de infância de classe média e classe média alta, nas quais, as crianças têm acesso à tecnologia. É importante salientar que outras produções podem surgir a partir de outros conceitos de infância.

\section{JUEGOS Y JUGUETES: \\ UMA BREVE INTERVENCIÓN QUE UNE LA INFANCIA Y LA ESCUELA}

\section{Resumen}

Este breve estudio examina los juegos y juguetes que une actualmente la infancia y la escuela. Se utilizó la investigación bibliográfica llevada a cabo por tres puntos: primero se analizan las puntuaciones de información en la historia de la infancia, los juguetes y la escuela. Después, estas son las características de los juguetes infantiles y hoy, después de articular la relacción de la escuela con los niños y los juguetes nuevos. El estudio demostró que los cambios sociales que ocurrieron en la historia influyeron en la formación de la infancia contemporánea y la relación de este con los juguetes y juegos, dejando la tarea de articular la escuela pasado y presente, así como producir reflexiones sobre las producciones de hoy en día.

Palabras-clave: Infância; juguetes; juegos; escuela. 


\section{Referências}

ARIÈS, Philippe. História Social da Criança e da Família. Trad. Dora Flaksman. Rio de Janeiro: LTC, 1981.

CORAZZA, Sandra Mara. Uma vida de professora. Ijuí: Ed. Unijuí, 2005. . História da infância sem fim. Ijuí: Unijuí, 2000.

Infância \& Educação: era uma vez... quer que conte outra vez? Rio de Janeiro: Vozes, 2002.

DORNELLES, Leni Vieira. Infâncias que nos escapam: da criança na rua à criança cyber. Petrópolis, RJ: Vozes, 2005.

GONÇALVEZ, Ana do Carmo Goulart. Contextualização da infância no espaço urbano: os possíveis efeitos da globalização. 2004/2005. Disponível em: http://www.seer.furg.br/ojs/index.php/momento/article/viewFile/607/154> Acesso em: 10 nov. 2008.

HEYWOOD, Colin. Uma história da infância. Porto Alegre: Artmed, 2004.

KUHLMANN, M. Infância e Educação Infantil: uma abordagem histórica. Porto Alegre: Mediação, 1998.

KISHIMOTO, Tizuko Morchida. O jogo, brinquedo, brincadeira e a educação. São Paulo, Cortez,1999.

LEVIN, Esteban. Rumo a uma infância virtual?: a imagem corporal sem corpo; trad. Ricardo Rosenbush. Petrópolis, RJ: Vozes, 2007.

MACHADO, João Luís de Almeida. Brinquedos ou Computadores? 2008. Disponível em: http://hdibrasil.com.br/index2.php?option=com_content\&do_pdf=1\&id=543 Acesso em: 14 nov. 2008.

ELIAS, Norbert (1897-1990). O processo civilizador: uma história dos costumes. Rio de Janeiro: Jorge Zahar Editor, 1994.

ELIAS, Norbert (1897-1990). O processo civilizador: Formação do Estado e Civilização. Rio de Janeiro: Jorge Zahar Editor, 1993.

PERROT, Michelle (Orga.). História da vida privada. São Paulo: Companhia das Letras, 2003.

POSTMAN, Neil. O desaparecimento da infância. Rio de Janeiro: Graphia, 1999. 
Data de recebimento: $10 / 08 / 2010$

Data de aceite: 10/09/2010 